\title{
Early Detection of COPD: An Opportunistic Case Finding Study in Smokers and Ex-Smokers Visiting a Medical Centre
}

\author{
Ariel Rokach' \\ Abraham Bohadana $\mathbb{D}^{\prime}$ \\ Ofir Kotek ${ }^{2}$ \\ Chen-Chen Shuali' \\ Hava Azulai' \\ Polina Babai ${ }^{3}$ \\ Yossi Freier-Dror ${ }^{3}$ \\ Gabriel Izbicki (D)'
}

\begin{abstract}
'Respiratory Research Unit, Pulmonary Institute, Department of Medicine, Shaare Zedek Medical Center and Faculty of Medicine, Hebrew University of Jerusalem, Jerusalem, 9103I, Israel;

${ }^{2}$ Department of Medicine, Shaare Zedek Medical Center and Faculty of Medicine, Hebrew University of Jerusalem, Jerusalem, 9103I, Israel; ${ }^{3}$ Mashav Applied Research, Jerusalem, 9332005, Israel
\end{abstract}

Background: Different case finding approaches have been used to identify early COPD. The objective of this study was to assess the feasibility and the yield of opportunistic early COPD case finding in visitors to a large medical centre.

Patients and Methods: From May 2014 to June 2017, we consecutively recruited adults aged $\geq 18$ years visiting the Shaare Zedek Medical Center, in Jerusalem. Our 3-step intervention included: a) pre-screening for symptoms with the 5-item "Could it be COPD?" questionnaire (score $=0-5 \mathrm{pts}$ ); b) pre-BD spirometry; and c) referral to a caregiver. Airflow obstruction was defined by a FEV1/FVC $<0.7$. Spirometry results were used as an incentive to promote smoking cessation and quit rates were verified by phone survey 3 months after the intervention.

Results: A total of 1001 subjects (956 smokers; 45 ex-smokers) were recruited. Mean (SD) age was 48.3 years (13.5). Airflow obstruction was detected in 180 (18\%) subjects of whom $142(78.9 \%)$ were unaware of it, including 27 subjects with severe $(50 \% \geq$ FEV $1 \leq 30 \%$ predicted) $(\mathrm{n}=25)$ or very severe $(\mathrm{FEV} 1<30 \%$ predicted $)(\mathrm{n}=2)$ obstruction. Multiple logistic regression analysis found that age, BMI, cigarette smoking (p.y.) and a "Could it be COPD?" questionnaire score $\geq 3$ points correctly classified $83.3 \%$ of cases of airflow obstruction. At follow-up, 54.5\% of participants reported smoking as usual, 30.9\% reduced smoking [mean $(\mathrm{SD})=10.1 \pm 7.8$ cigarettes $/$ day], $7.4 \%$ increased smoking $[$ mean $(\mathrm{SD})=9.2$ \pm 6.3 cigarettes/day] and $7.2 \%$ claimed smoking cessation. Among obstructed subjects, $38.7 \%$ had visited a physician because of COPD, while $20.7 \%$ were taking a new respiratory medication.

Conclusion: Early COPD case finding was feasible and effective in identifying undiagnosed airflow obstruction among visitors to a medical centre. Smoking cessation counselling based on spirometry promoted a small but clinically meaningful cessation rate.

Keywords: early COPD, case finding, hospital visitors, airway obstruction, cigarette smoking, Could it be COPD?, screening, spirometry

\section{Introduction}

Chronic obstructive pulmonary disease (COPD) is a leading cause of morbidity and mortality worldwide. ${ }^{1}$ In the USA, COPD is the third leading cause of death, and it is estimated that it affects $14 \%$ of Americans above the age of $40 .^{2}$ In Israel, in a large-scale survey, $22 \%$ of smokers were diagnosed with COPD by spirometry. ${ }^{3}$

COPD is insidious, being usually detected when lung function has significantly deteriorated, leading to considerable underdiagnosis. ${ }^{4-6}$ In this context, early 
identification of COPD is becoming an important health issue since it provides an opportunity to prevent lung function decline, reduce the burden of symptoms, and improve the subjects' quality of life. ${ }^{7}$ Guidelines developed by the Global Initiative for Chronic Obstructive Lung Disease (GOLD) and by the US Preventive Services Task Force (USPFTS) do not recommend COPD screening for asymptomatic smokers, only for smokers with symptoms suggestive of COPD. ${ }^{4,8}$ An acceptable strategy is the identification of at-risk subjects via a pre-screening questionnaire, followed by simple spirometry ie spirometry administered without a bronchodilator (BD) and, if applicable, diagnostic spirometry. ${ }^{8}$

Smokers visiting a primary clinic because of respiratory symptoms are a natural target for COPD case finding. However, several obstacles exist for implementing case finding in this setting such as limited clinician time and lack of expertise to perform good quality spirometry, or simply unavailability of spirometers. Another important, practical aspect is that the pre-screening questionnaire should be short, easy to administer, and straightforward in interpretation.

With the above considerations in mind, we carried out a pilot study to examine the feasibility and the yield of an opportunistic case finding intervention in current and former smokers visiting a large medical centre. We chose this population not only because it is at hand, but also because a visit to a health facility might motivate smokers to reflect about their own health and undergo screening. As screening tools we used the "Could it be COPD?" questionnaire developed by GOLD ${ }^{4}$ and simple spirometry. Additionally, we used lung function testing as a "teachable moment" to encourage the participants to quit smoking. To assess the efficacy of this mini-counselling session, we conducted a telephone survey three months after the intervention.

\section{Methods}

\section{Study Population}

The study population consisted of an opportunity sample of current and former smokers 18 years of age or older, visiting the Shaare Zedek Medical Center (SZMC) in Jerusalem, recruited through advertising posters placed at strategic locations in the hospital. We excluded hospitalised patients and subjects seeking medical help. Assessments were conducted in a room situated just in front of the Emergency Department, a place highly frequented by visitors on a daily basis.

\section{Ethics Approval}

The "Helsinki Ethics Committee of the Shaare Zedek Medical Center" approved all study procedures (Reg: 16/ 14 SZMC); all participants provided written informed consent prior to any procedures. The study complied with the Declaration of Helsinki on ethical principles for medical research involving human subjects.

\section{Research Team}

The team dispensing the intervention was formed by a certified pulmonologist and a technician proficient in performing spirometry.

\section{Case Finding Process}

The case finding process involved three steps namely riskassessment using a pre-screening questionnaire, simple spirometry, and referral of participants to their regular physician for further evaluation and follow-up.

\section{Pre-Screening Questionnaire}

Upon arrival, all participants completed a questionnaire on demographics and smoking habits and the "Could it be COPD?" questionnaire, which consists of five questions scored on a 5-point scale as follows: 1. Do you cough several times most days? 2. Do you bring up phlegm or mucus most days? 3. Do you get out of breath more easily than others of your age? 4 . Are you older than 40 years? 5 . Are you a current smoker or an ex-smoker? Subjects with three or more positive responses are considered at higher risk of having COPD. ${ }^{4}$

\section{Spirometry}

A qualified technician performed simple spirometry using a portable electronic spirometer (Pony Desktop Spirometer, Cosmed Srl, Italy). Calibration was done at the beginning of the day as recommended by the manufacturer. Subjects in the sitting position performed maximal forced expiratory manoeuvres after maximal inspiration. At least three forced expiratory manoeuvres, satisfactory according to recommended criteria, ${ }^{9}$ were recorded. From the various indices automatically calculated from the best curve, three were retained for analysis: forced expiratory vital capacity (FVC); forced expiratory volume in one second (FEV1); and the FEV1/FVC ratio. Results were expressed as percentage of the predicted. Pre-BD airflow obstruction was diagnosed in subjects with a FEV1/FVC value $<0.70$. Four grades of severity 
were considered namely: a. Mild: FEV1 $\geq 80 \%$ predicted; b. Moderate: FEV1 $<80 \%$ but $\geq 50 \%$ predicted; c. Severe: FEV1 $<50 \%$ but $\geq 30 \%$ predicted, and d. Very severe: FEV1 $<30 \%$ predicted. ${ }^{4}$ Subjects with airflow limitation who had no knowledge of previous lung function abnormality were considered to have undiagnosed airway obstruction.

\section{Smoking Cessation Counselling and Follow-Up}

At each session, one of the pulmonologists participating in the study reviewed the spirometry. We used the test results to provide counselling on smoking cessation: subjects with normal spirometry were encouraged to stop smoking to prevent disease, while those with airflow obstruction were encouraged to stop smoking to avoid further deterioration. All received a brief explanation on how cigarette smoking causes COPD, and were informed that existing COPD therapy is merely symptomatic, smoking cessation being the only measure capable to avoid the onset and/or the progression of the disease. Finally they were briefed on the best existing evidence-based treatments for smoking cessation, and advised to quit smoking. Test interpretations were mailed to all participants, with recommendation to further discuss the screening results with their personal physicians and obtain confirmatory spirometry when necessary. Three months after the intervention, we did a telephone survey to inquire about the subjects' smoking habits, current medical assistance and respiratory medications.

\section{Statistical Analysis}

Statistical analysis was conducted using the SPSS (Version 21.0) statistical software. For all interval and ratio variables, means and standard deviations were calculated, and t-tests were carried out to compare subjects with and without airflow obstruction, and between females and males. For all nominal variables, absolute frequencies and percentages were calculated. Multiple logistic regression analysis was used to determine the factors associated with airway obstruction $(\mathrm{FEV} 1 / \mathrm{FVC}<0.7)$ taken as dependent variable. Several independent variables, selected on the basis of their clinical importance, were entered in the model, using a stepwise forward selection. The discrimination power of the fitted logistic model was expressed by the area under the curve (AUC) of receiver operating characteristic (ROC) curves. Student's paired $t$-test was carried out to compare smoking habits at intervention and three months later. The criterion for significance was a $\mathrm{P}$-value $<0.05$

\section{Results}

In total, we recruited 1001 subjects [956 (95.5\%) smokers; 45 (4.5\%) ex-smokers], of whom 755 were men (75.4\%) and 246 women (24.6\%). The mean (SD) age was $48.3 \pm 13.5$ years. The mean BMI (SD) was 26.8 (4.7) $\mathrm{kg} / \mathrm{m} 2$. The mean (SD) cigarette smoking was 32.5 (25.7) pack years. Table 1 presents the subjects' baseline characteristics.

\section{Airway Obstruction}

As shown in Table 2, the study identified 180 (18\%) cases of airway obstruction, of which 139 (77\%) were of mild to moderate severity. Furthermore, of the 180 obstructed subjects $142(78.9 \%)$ were unaware of this abnormality; obstruction was mild to moderate in 115 and severe or very severe in 27 . Overall, the proportion of cases grouped by severity was similar in males compared with females, both for the group as a whole and for subjects with undiagnosed obstruction. The prevalence of airflow obstruction increased steadily with age, from $7.4 \%$ in subjects younger than 34 years of age to $43.6 \%$ in subjects 71 years of age or older (Figure 1). The prevalence of airflow obstruction increased with smoking exposure, from $8.1 \%$ in subjects smoking $\leq$ 10 pack years to $30.3 \%$ in subjects smoking $\geq 40$ pack years (Figure 2).

Table I Baseline Characteristics of Participants

\begin{tabular}{|l|c|c|c|}
\hline Variable & All & Females & Males \\
\hline Participant n (\%) & $100 I(100)$ & $246(24.6)$ & $755(75.4)$ \\
\hline Parameter & & & \\
Age, yr. & $48.3 \pm 13.5$ & $51.3 \pm 12.0$ & $47.4 \pm 13.8$ \\
Age median, Min-Max, yr & $49,18-87$ & $53,21-78$ & $48,18-87$ \\
Height, cm & $171.3 \pm 8.5$ & $163.0 \pm 6.3$ & $174.0 \pm 7.2$ \\
Weight, kg & $78.8 \pm 15.5$ & $69.8 \pm 13.7$ & $81.8 \pm 14.9$ \\
BMI, kg/m2 & $26.8 \pm 4.7$ & $26.3 \pm 5.1$ & $27.0 \pm 4.5$ \\
\hline Smoking & & & \\
Smoker, n (\%) & $956(95.5)$ & $235(95.5)$ & $721(95.5)$ \\
Former Smoker, n (\%) & $45(4.5)$ & $11(4.5)$ & $34(4.5)$ \\
Cigarette smoking in p.y. & $32.5(25.7)$ & $31.2(22.8)$ & $33.0(26.5)$ \\
Age of Ist cigarette, yr. & $18.7 \pm 5.5$ & $19.8 \pm 6.8$ & $18.4 \pm 4.9$ \\
Cigarettes per day, n & $21.8 \pm 12.5$ & $20.0 \pm 11.5$ & $22.5 \pm 12.7$ \\
\hline
\end{tabular}

Note: Values are mean (SD) except when stated otherwise. 
Table 2 Frequency and Severity of Airway Obstruction in Participants Stratified by Sex

\begin{tabular}{|c|c|c|c|c|c|c|}
\hline \multirow[t]{2}{*}{ Airway Obstruction } & \multicolumn{2}{|l|}{ Both Sexes } & \multicolumn{2}{|l|}{ Females } & \multicolumn{2}{|l|}{ Males } \\
\hline & Observed & Undiagnosed & Observed & Undiagnosed & Observed & Undiagnosed \\
\hline $\mathrm{n}, \%^{\mathrm{a}}$ & $180(18.0)$ & $142(14.2)$ & $50(5.0)$ & $35(3.5)$ & $130(13.0)$ & $107(10.7)$ \\
\hline Mild, n (\%b) & $43(23.9)$ & $38(26.8)$ & $14(28.0)$ & $12(34.3)$ & $29(22.3)$ & $26(24.3)$ \\
\hline Moderate, $\mathrm{n}\left(\%^{\mathrm{b}}\right)$ & $96(53.3)$ & $77(54.2)$ & $23(46.0)$ & $16(45.7)$ & $73(56.2)$ & $61(57.0)$ \\
\hline Severe, n $\left(\%^{\mathrm{b}}\right)$ & $38(21.1)$ & $25(17.6)$ & II (22.0) & $6(17.1)$ & $27(20.8)$ & $19(17.8)$ \\
\hline Very severe, $\mathrm{n}\left(\%^{\mathrm{b}}\right)$ & $3(1.7)$ & $2(1.4)$ & $2(4.0)$ & I (2.9) & $\mathrm{I}(0.8)$ & I (0.9) \\
\hline
\end{tabular}

Notes: ${ }^{\text {PPercent }}$ of total population. ${ }^{\mathrm{b}}$ Percent of class.

Abbreviations: Obs, observed; Und, undiagnosed.

\section{GOLD Symptom Questionnaire}

Figure 3 shows that the frequency of airway obstruction increased with increase of the "Could it be COPD?" questionnaire score, from $6.8 \%$ in subjects with a score of 1 to $37.4 \%$ for those with a score of 5 . The risk for airway obstruction was $10.5 \%$ among participants with a "Could it be COPD?" questionnaire score of $1-2$ and of $26.3 \%$ among those with a score of $3-5$ points.

\section{Predictors of Airflow Obstruction}

Multiple logistic regression analysis found that four factors were independently associated with airflow obstruction: a) age; b) BMI; c) cigarette smoking in pack years; and a d) "Could it be COPD?" questionnaire score $\geq 3$ points (Table 3). The model correctly classified $83.3 \%$ of cases of airway obstruction. The discrimination ability of the model, assessed by means of ROC curves, showed a curve displaced to the optimal left upper corner, with a resulting AUC of 0.763 , indicating a good discrimination ability for the model (Figure 4).

\section{Telephone Survey}

Table 4 shows the results of the follow-up survey. At three months, we were able to reach 864 participants, of whom 824 smoked at enrolment versus 40 ex-smokers. At follow-up, none of the ex-smokers had resumed smoking. In total, $54.5 \%$ of subject smoking at enrolment continued to smoke as usual; $30.9 \%$ reported a reduction in the number of cigarettes/day [mean $\pm \mathrm{SD}=10.1$ (7.8)]; $7.4 \%$ an

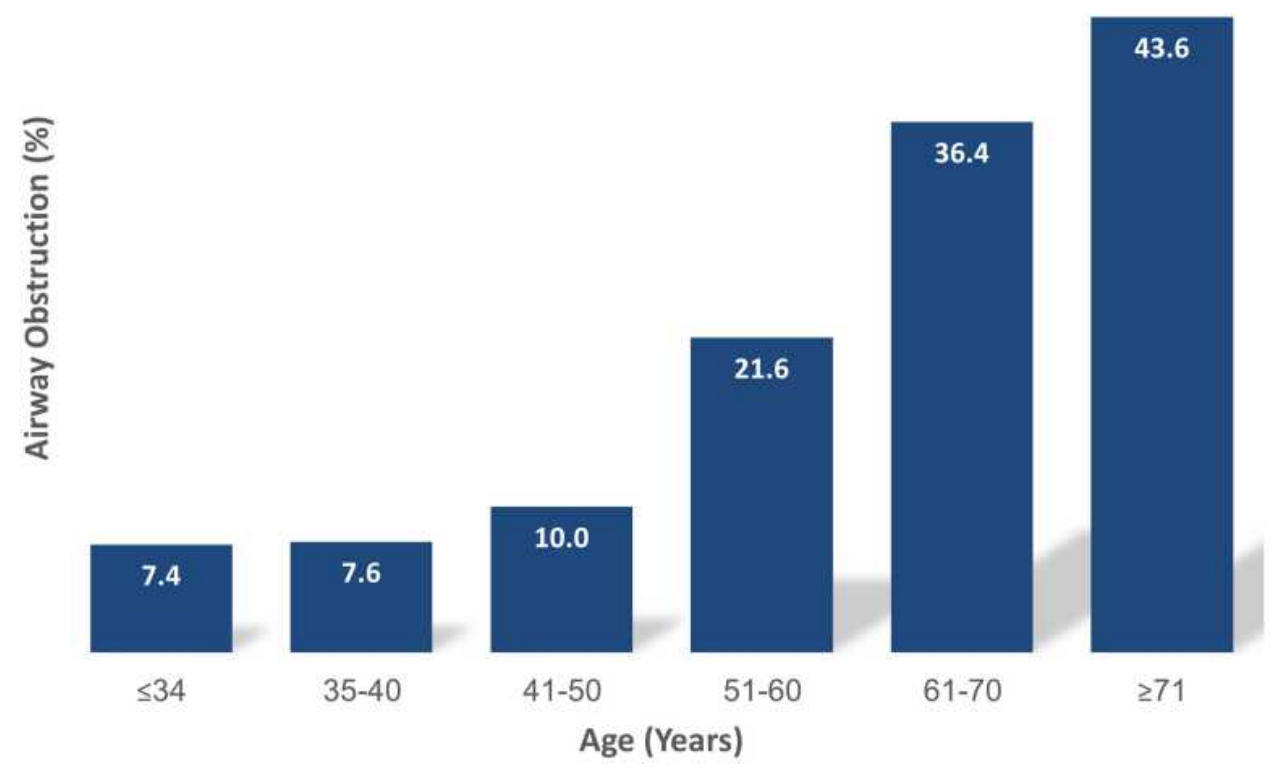

Figure I Prevalence of airway obstruction in the participants stratified by age. Prevalence of airflow obstruction was relatively constant, around $7.5 \%$, up to age 40 years, when it increased steadily to over $40 \%$ at age $\geq 7$ l years. 


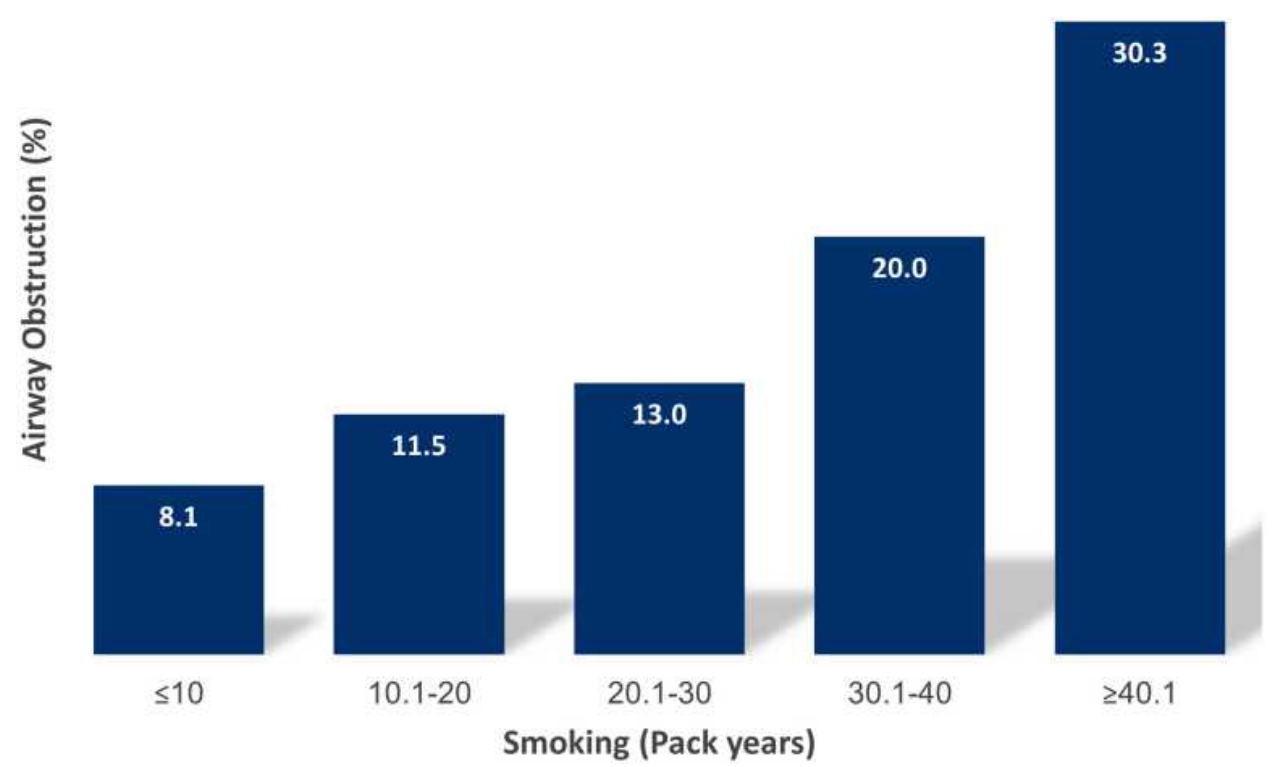

Figure 2 Prevalence of airflow obstruction in participants stratified by cigarette smoking. Prevalence of airflow obstruction remained below 10\% for a cigarette consumption up to 10 p.y. From that point onwards it increased steadily to values beyond $30 \%$ for a cigarette consumption $\geq 40$ p.y.

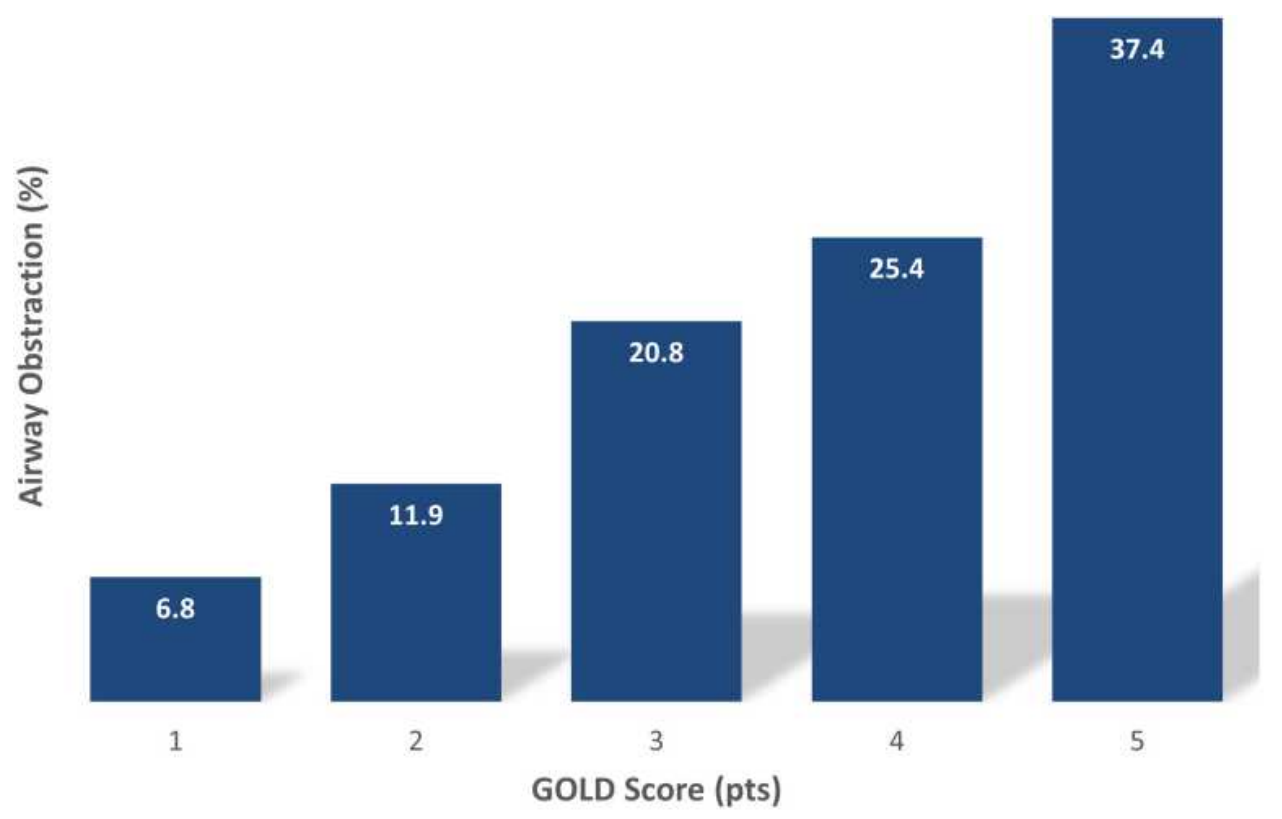

Figure 3 Prevalence of airflow obstruction in participants stratified by GOLD symptom score. Prevalence of airway obstruction increased linearly with an increase in GOLD symptom score, from $6.8 \%$ for subjects with a score of I pt to almost $40 \%$ for those with a score of 5 pts.

increase in the number of cigarettes/day [mean $\pm \mathrm{SD}=9.2$ (6.3)]; and 7.2\% claimed smoking cessation. No significant differences were apparent in the smoking behaviour of the two sexes or between obstructed versus nonobstructed subjects.

Among participants with airflow obstruction, 38.7\% reported a visit to a physician because of COPD, and $20.7 \%$ that they were taking a new respiratory medication. Among participants without airflow obstruction,
$15.6 \%$ reported seeing a physician, and $4.3 \%$ taking a new respiratory medication $(p<0.001)$.

\section{Discussion}

COPD is an insidious disease, becoming apparent when symptoms appear in more advanced stages, causing underdiagnosis and justifying case finding. ${ }^{4}$ COPD case finding in symptomatic smokers is currently recommended, but there is no consensus on the best strategy to reach and 
Table 3 Predictors of Airway Obstruction by Forward, Stepwise Logistic Regression Analysis

\begin{tabular}{|l|r|r|r|r|}
\hline Variable & B & S.E. & Sig & OR (95\% C.I) \\
\hline Age & 0.047 & 0.008 & 0.000 & $1.048(1.032-1.066)$ \\
BMI & -.100 & 0.022 & 0.000 & $0.905(0.868-0.944)$ \\
Smoking (p.y) & 0.009 & 0.004 & 0.013 & $1.009(1.002-1.016)$ \\
"Could it be COPD?" & 0.783 & 0.191 & 0.000 & $2.187(1.505-3.179)$ \\
score $\geq 3$ & & & & \\
\hline
\end{tabular}

Abbreviations: B, slope; S.E, standard error; Sig, significance; OR, odds ratio.

screen these subjects. In this study, we explored the use of opportunistic case identification of adults at risk for COPD among visitors to a large medical centre. We found the intervention to be feasible in this context, resulting in the identification of airway obstruction in $18 \%$ of participants, with nearly $80 \%$ of cases being undiagnosed. Using the spirometry results to provide counselling resulted in smoking cessation in $7.2 \%$ of smokers, and in new respiratory medication in $20.7 \%$ of obstructed smokers.

This study showed that $18 \%$ of smokers in this opportunistic sample were diagnosed with airflow obstruction. The prevalence of airflow obstruction among subjects older than 40 years and among subjects smoking more than 10 pack years exceeded $20 \%$. The score of the "Could it be COPD?" questionnaire was associated with

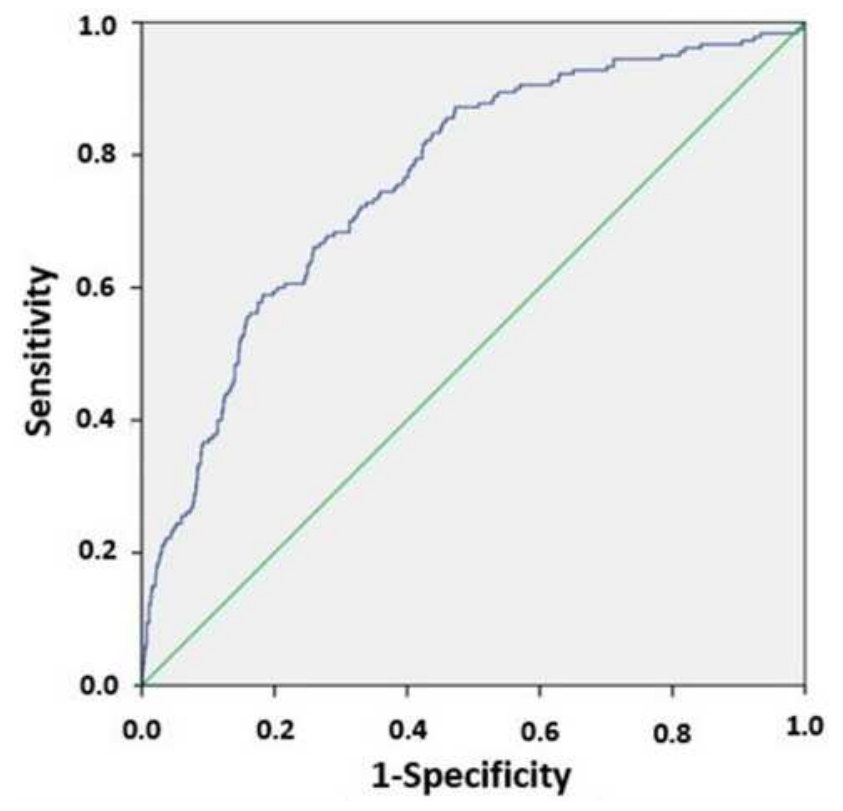

Figure 4 Logistic regression for airway obstruction according to age, BMI, cigarette smoking and GOLD score. ROC curve expressing the discrimination power of the logistic model presented in Table 3 including, as dependent variable, airway obstruction (FEVI/FVC < 0.7), and as independent variables, age, BMI, cigarette smoking (p. y.) and GOLD score $\geq 3$. The curve is displaced to the upper left corner, indicating good discriminating power of the model $(A \cup C=0.763)$.
Table 4 Impact of Smoking Cessation Counselling on Smoking Habits of Participants Stratified by Gender

\begin{tabular}{|l|l|l|l|}
\hline Participants & All & Females & Males \\
\hline Responded follow up call, n (\%) & $864(100)$ & $221(25.6)$ & $643(74.4)$ \\
- Smokers at entry n (\%) & $824(95.4)$ & $213(96.4)$ & $611(95.0)$ \\
- Ex-smokers at entry n, (\%) & $40(4.6)$ & $8(3.6)$ & $32(5.0)$ \\
\hline Smoking at follow-up & & & \\
- As usual n (\%) & $449(54.5)$ & $123(57.7)$ & $326(53.4)$ \\
- More than at entry n (\%) & $61(7.4)$ & $13(6.1)$ & $48(7.9)$ \\
$\Delta$ cigarettes/day Mean (SD) & $9.2(6.3)$ & $7.8(5.1)$ & $9.6(6.6)$ \\
- Less than at entry n (\%) & $255(30.9)$ & $65(30.5)$ & $190(31.1)$ \\
$\Delta$ cigarettes/day Mean (SD) & $10.1(7.8)$ & $10.8(8.6)$ & $9.8(7.5)$ \\
- Stopped smoking n (\%) & $59(7.2)$ & $12(5.6)$ & $47(7.7)$ \\
\hline
\end{tabular}

airflow obstruction, with a score of three points or more being associated with a prevalence rate of $26.3 \%$. While most undiagnosed cases involved mild to moderate obstruction, a clinically meaningful minority of participants had severe $(n=25)$ to very severe $(n=2)$ obstruction. These results are consistent with previous studies showing that airflow obstruction is common among symptomatic smokers aged 40 years and above who have smoked more than 10 pack years. ${ }^{10}$ Furthermore, consistent with the results of the large European Community Respiratory Health Survey (ECRHS) study in young adults, ${ }^{11}$ we found a prevalence of airflow obstruction of $7.5 \%$ in smokers younger than 35 years.

Routine spirometry is generally not recommended for adults without symptoms suggestive of COPD (ie progressive dyspnoea, chronic cough, and/or sputum production) because asymptomatic, mild airflow obstruction is not considered to be amenable to treatment. ${ }^{8,12}$ However, waiting for patients to report symptoms may miss many who have COPD, as individuals with airway obstruction due to COPD may not report symptoms, and might deteriorate without treatment. Consistent with survey data ${ }^{13}$ our results show that a proportion of smokers with airway obstruction had low "Could it be COPD?" questionnaire scores $(<3$ pts.) and that, in contrast, a sizeable proportion of smokers with high "Could it be COPD?" questionnaire scores ( $\geq 3$ pts.) had normal spirometry. Telling these subjects they do not fit the current diagnostic criteria for COPD and that, consequently, they are not candidates for COPD pharmacotherapy, may convey the disastrous message that their current level of smoking is safe or, even worse that they belong to a special group of subjects "resistant" to the effects of cigarette smoking. To further examine the significance of these subsets of smokers we 
planned a secondary analysis of our data that will be reported in a companion paper.

Our findings are consistent with previous studies supporting the use of screening spirometry to promote smoking cessation. ${ }^{14-16}$ Even though our cessation counselling session was minimal, at three months 59 participants (7.2\%) claimed they had stopped smoking. This small but clinically meaningful quit rate may have resulted from the participants' positive perception of our team as a trustworthy and knowledgeable source of information when it comes to smoking, and by the visualisation, through spirometry, of the negative consequences of smoking. ${ }^{17}$ Although smoking status could not be verified by biologic markers such as expired carbon monoxide (CO) or cotinine measurements, we believe there was no bias toward over-reporting, as no particular reason existed for the participants to be eager to convey a good impression. Other than smoking cessation, 255 smokers (30.9\%) reported an average decrease of 10 cigarettes in the number of cigarettes smoked per day. However, although it goes in the positive direction, smoking reduction cannot be considered an acceptable goal of case finding intervention. In fact, because of compensatory smoking, smoking reduction is unlikely to be beneficial in lowering the risks associated with smoking in a meaningful way. ${ }^{18}$

The diagnosis of COPD requires a FEV1/FVC ratio less than 0.7 after the inhalation of a BD. ${ }^{4}$ We carried out spirometry without a BD test for several reasons. First and foremost, including the BD test in the protocol would have lengthened the intervention considerably, making it impractical and much less acceptable - if at all - by the visitors. Furthermore, the role of BD reversibility testing in COPD case finding has been questioned by experts ${ }^{19}$ and in guidelines. ${ }^{20}$ Arguments for not performing the test include: (i) daily, spontaneous fluctuation of FEV1; (ii) lack of reproducibility of the BD test; (iii) lack of significance for changes in post-BD FEV1 below $400 \mathrm{~mL}$; and (iv) arbitrariness of definition of a significant test. ${ }^{21} \mathrm{~A}$ final and more important argument was that patients with COPD may exhibit true BD reversibility, independently from asthma. By consequence, excluding all subjects with a positive BD test could result in a substantial risk of COPD underdiagnosis. This hypothesis was convincingly demonstrated by Kjeldgaard and colleagues $^{21}$ who questioned the need for the BD test in the diagnostic screening algorithm in early COPD finding. Incidentally, since most of our participants were heavy smokers, we think that a positive BD test would be more likely to be due to asthma-COPD overlap than pure asthma, although we cannot exclude the hypothesis of undiagnosed asthma.

This study has strengths and limitations. First, our opportunistic approach may have selected smokers who worried about their health condition; however, rather than a drawback, this "bias" would increase the proportion of higher-risk participants likely to be screened, which was the goal of the case finding intervention. This strategy resulted in participants being very cooperative and expressing genuine interest in the program. Another strength was the presence of a pulmonary physician in the intervention team. This made our explanations on lung function and smoking trustworthy and, additionally, may have influenced the message of the mini-counselling session on smoking cessation more positively than what might have been achieved by a non-specialist. Finally, spirometry was performed by technicians with training and expertise in doing tests with the quality required for research purposes, which is higher than might be encountered in some primary care centres.

As for the limitations, the diagnosis of COPD was not confirmed by a comprehensive, individual clinical assessment; however, the goal of early COPD case finding is to select subjects with a high likelihood of COPD, which must be confirmed post-screening. Additionally, the use of fixed FEV1/FVC $<0.7$ cut-off as a criterion of obstruction can result in some degree of over diagnosis in older subjects, overestimating the effectiveness of the intervention; however, for the purpose of screening, a higher sensitivity may be acceptable in older, higher-risk patients. ${ }^{22}$

In conclusion, this study showed that COPD case finding based on the use of the "Could it be COPD?" questionnaire as an objective measure of COPD-related respiratory symptoms, followed by pre-BD spirometry was feasible in the context of a visit to a hospital, and identified a sizable proportion of smokers with a provisional diagnosis of COPD. This short, simple and cheap intervention is amenable to implementation in non-medical settings like, for example, a shopping mall, pharmacy or even a grocery store. This "demedicalised" setting may encourage smokers and ex-smokers to undergo COPD screening more easily than in the more serious context of a medical visit. Simple, our case finding intervention can be performed by a single caregiver trained in spirometry and in basic counselling on smoking cessation. Further studies should explore the value of not restricting screening to symptomatic smokers, and should examine the risk of disease in asymptomatic smokers with obstruction as well as symptomatic smokers without obstruction. 


\section{Data Sharing Statement}

All participant-level data relevant to the study are included in the article. The study data are available from the corresponding author upon reasonable request, after removal of all personal identifiers, and after approval by the SZMC ethics committee.

\section{Acknowledgments}

The authors are indebted to Dr. Steve Kraman for revising and editing the manuscript. They also thank Mrs. Bracha Levy and Mrs. Yael Batan for performing spirometry, and Drs. Nissim Arish, Ayal Romem, George Kalak and David Kupferberg for helping with recruitment.

\section{Funding}

This study was funded by an unrestricted grant from Novartis, Israel.

\section{Disclosure}

The authors report no conflict of interest in this study.

\section{References}

1. World Health Organization. Chronic Obstructive Pulmonary Disease. Available from: https://www.who.int/news-room/fact-sheets/detail/ chronic-obstructive-pulmonary-disease-(copd). Accessed December 11, 2020.

2. Tilert T, Dillon C, Paulose-Ram R, Hnizdo E, Doney B. Estimating the US prevalence of chronic obstructive pulmonary disease using preand post-bronchodilator spirometry: the National Health and Nutrition Examination Survey (NHANES) 2007-2010. Respir Res. 2013;14 (1):103. doi:10.1186/1465-9921-14-103

3. Stav D, Raz M. Prevalence of Chronic Obstructive Pulmonary Disease among smokers aged 45 and Up in Israel. IMAJ. 2007;9(11):800-802.

4. Global strategy for diagnosis, management and prevention of COPD. February 2020, Available from: http://www.goldcopd.org. Accessed October 30, 2020.

5. Hill K, Goldstein RS, Guyatt GH, et al. Prevalence and underdiagnosis of chronic obstructive pulmonary disease among patients at risk in primary care. CMAJ. 2010;182(7):673-678. doi:10.1503/cmaj.091784

6. Miravitlles M, Soriano JB, Garcia-Rio F, et al. Prevalence of COPD in Spain: impact of undiagnosed COPD on quality of life and daily life activities. Thorax. 2009;64(10):863-868. doi:10.1136/ thx.2009.115725

7. Tinkelman DG, Price DB, Nordyke RJ, Halbert RJ. COPD Screening efforts in primary care: what is the yield? Prim Care Respir J. 2007;16 (1):41-48. doi:10.3132/pcrj.2007.00009

8. Guirguis-Blake JM, Senger CA, Webber EM, Mularski RA, Whitlock EP. Screening for chronic obstructive pulmonary disease: evidence report and systematic review for the US preventive Services Task Force. JAMA. 2016;315(13):1378-1393. doi:10.1001/ jama.2016.2654
9. Pellegrino R, Viegi G, Brusasco V, et al. Interpretative strategies for lung function tests SERIES "ATS/ERS TASK FORCE: STANDARDISATION OF LUNG FUNCTION TESTING". Eur Respir J. 2005;26(5):948-968. doi:10.1183/09031936.05.0 0035205

10. Katsimigas A, Tupper OD, Ulrik CS. Opportunistic screening for COPD in primary care: a pooled analysis of 6710 symptomatic smokers and ex-smokers. J Chron Obstruct Pulmon Dis. 2019;14:1633-1638. doi:10.2147/COPD.S204190

11. de Marco R, Accordini S, Cerveri I, et al.; European Community Respiratory Health Survey Study Group. An international survey of chronic obstructive pulmonary disease in young adults according to GOLD stages. Thorax. 2004;59(2):120-125. doi:10.1136/thorax.20 03.011163

12. Qaseem A, Wilt TJ, Weinberger SE, et al. Diagnosis and management of stable chronic obstructive pulmonary disease: a clinical practice guideline update from the American College of Physicians, American College of Chest Physicians, American Thoracic Society, and European Respiratory Society. Ann Intern Med. 2011;155(3):179. doi:10.7326/0003-4819-155-3-201108020-00008

13. Mannino DM, Gagnon RC, Petty TL, Lydick E. Obstructive lung disease and low lung function in adults in the United States: data from the National Health and Nutrition Examination Survey, 1988-1994. Arch Intern Med. 2000;160(11):1683-1689. doi:10.1001/archinte.160.11.1683

14. Górecka D, Bednarek M, Nowiński A, et al. Diagnosis of airflow limitation combined with smoking cessation advice increases stop-smoking rate. Chest. 2003;123(6):1916-1923. doi:10.1378/ chest.123.6.1916

15. Bednarek M, Gorecka D, Wielgomas J, et al. Smokers with airway obstruction are more likely to quit smoking. Thorax. 2006;61 (10):869-873. doi:10.1136/thx.2006.059071

16. Parkes G, Greenhalgh T, Griffin M, et al. Effect on smoking quit rate of telling patients their lung age: the Step 2 quit randomized controlled trial. BMJ. 2008;336(7644):598-600. doi:10.1136/ bmj.39503.582396.25

17. Slama KJ, Redman S, Cockburn J, SansonFisher R. Community views about the role of general practitioners in disease prevention. Fam Pract. 1989;6(3):203-209. doi:10.1093/fampra/ 6.3.203

18. Hughes J, Carpenter MJ. Does smoking reduction increase future cessation and decrease risk? A qualitative review. Nicotine Tob Res. 2006;8(6):739-749. doi:10.1080/14622200600789726

19. Mannino D. Defining chronic obstructive pulmonary disease ... and the elephant in the room. Eur Respir J. 2007;30(2):189-190. doi: $10.1183 / 09031936.00058707$

20. Chronic obstructive pulmonary disease in over 16s: diagnosis and management. NICE guideline [NG115]; 05 December 2018 [Updated 26 July 2019]. Available from: https://www.nice.org.uk/guidance/ ng115. Accessed November 3, 2020.

21. Kjeldgaard P, Dahl R, Lokke A, Ulrik CS. Detection of COPD in a high-risk population: should the diagnostic wor-up include bronchodilator reversibility testing? Int $J$ COPD. 2015;10:407-414. doi:10.2147/COPD.S76047

22. Celli BR, Halbert RJ, Isonaka S, Schau B. Population impact of different definitions of airway obstruction. Eur Respi J. 2001;22 (2):268-273. doi:10.1183/09031936.03.00075102 


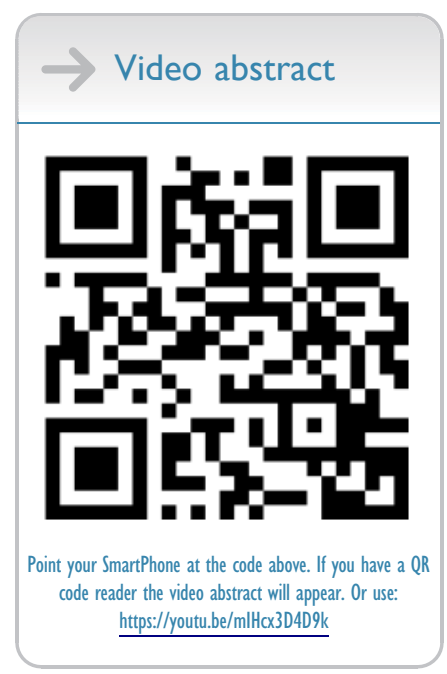

International Journal of Chronic Obstructive Pulmonary Disease

\section{Publish your work in this journal}

The International Journal of COPD is an international, peer-reviewed journal of therapeutics and pharmacology focusing on concise rapid reporting of clinical studies and reviews in COPD. Special focus is given to the pathophysiological processes underlying the disease, intervention programs, patient focused education, and self management protocols. This journal is indexed on PubMed Central, MedLine and CAS. The manuscript management system is completely online and includes a very quick and fair peer-review system, which is all easy to use. Visit http://www.dovepress.com/testimonials.php to read real quotes from published authors. 